\title{
Students as scientists' co-pilots at the onset of technology transfer: a two-way learning process
}

\author{
Ferran Giones $^{1}$ (D) $\cdot$ Kari Kleine $^{2}$ (D) $\cdot$ Silke Tegtmeier $^{2}$ (D)
}

Accepted: 3 September 2021

(c) The Author(s) 2021

\begin{abstract}
To provide further knowledge and technology transfer to society, universities are exploring new collaborative models. These new models are regarded as promising alternatives to the patent-centric linear model. However, their implementation requires revising the roles of the actors in the technology transfer process and their relationships. While collaborative models could indeed be an attractive option for universities, there is limited evidence on how these collaboration processes could be effectively introduced. We use a longitudinal embedded multiple case study to explore the contribution of knowledge interactions between scientists and students in the preliminary steps of the technology transfer process. We investigate the learning dynamics between the focal actor, i.e., the scientist, and the students in a university setting to decipher how the introduction of such collaborative processes can contribute to knowledge and technology transfer. Our results suggest that students enrolled in an educational program can contribute to the scientist's interest and engagement in technology transfer. However, we find out that the extent of the students' contribution depends on the shared consensus over the technology function and the openness of the scientist to reconsider the technology's meaning. We contribute to the ongoing exploration of alternative models for technology transfer and the identification of additional roles that students can take in entrepreneurial university ecosystems.
\end{abstract}

Keywords Technology transfer models $\cdot$ University $\cdot$ Students $\cdot$ Scientist-student teams

JEL Classification I23 $\cdot \mathrm{L} 24 \cdot \mathrm{O} 31 \cdot \mathrm{O} 32$

\section{Introduction}

Universities strive to disseminate scientific knowledge and engage in technology transfer activities to contribute to economic development and to address societal issues (Alexander et al., 2018). Although the promotion of this expanded societal role of universities has been

Ferran Giones

ferran.giones@ets.uni-stuttgart.de

1 University of Stuttgart, Pfaffenwaldring 19, Stuttgart, Germany

2 Department of Technology and Innovation, University of Southern Denmark, Alsion 2, Sønderborg, Denmark 
part of innovation policy for decades now (Wright et al., 2007), there has been an increasing attention on the economic returns from the commercialization of research results, either in the form of royalties via technology licensing or through the participation in new science-based businesses (Knockaert et al., 2011). Considering the oftentimes disappointing results for the number of high-growth university spin-offs (Mustar et al., 2008; Siegel $\&$ Wright, 2015) and the low levels of income generated (with some exceptions) through licensing technology (Weckowska et al., 2018), it is not surprising that there is an intense debate on the present and future universities' technology transfer processes (Hayter, et al., 2018a, 2018b).

Arguably, the patent-centric linear models of technology transfer are not the only path to generate societal and economic impact (Fini, et al., 2018a, 2018b). In addition, the narrow focus on patenting can limit the participation of technology transfer offices (TTOs) in alternative paths or models for technology transfer (Bradley et al., 2013; Hayter, et al., 2018a, 2018 b). While the existing models work well for successful scientists that can assume multiple roles and deal with conflicting sources of pressure and tension (Casati \& Genet, 2014; Mangematin et al., 2014), they do not work well for young scientists or scientists in departments with limited technology transfer experience, lacking role models, or with scarce organizational support (Greven et al., 2020).

We build on prior observations studying how students in academic spin-offs contribute to bridge the distance between technology and market (Boh et al., 2016; Hayter et al., 2017) and propose to expand prior student entrepreneurship research to study how students can contribute in the early stage of a potential technology transfer process (before invention disclosure). More specifically, our research question is: how do students contribute, through an educational program, to the initiation of scientists' technology transfer processes?

We use a longitudinal embedded multiple case study design to observe four projects where scientists and engineering students work together in the context of a master's educational program in a university. This setting provides an excellent context to explore the research question, as the involved scientists are working on cutting-edge technologies but have only limited experience in technology transfer or academic entrepreneurship. Furthermore, possible market applications for the respective technologies have not yet been identified.

Our results are synthesized in an explanatory framework, which describes the different stages and the connecting mechanisms in the scientist-student team collaboration in the exploration of opportunities for technology transfer. In particular, we discuss how the consensus within the scientist-student team on the technology-market function and the flexibility (or rigidity) of the scientist's technology-market focus influence the contributions of students, allowing them to take a co-pilot role in the collaborative process. We contribute to the ongoing debate on collaborative models for technology transfer (Bradley et al., 2013), to the identification of additional functions that students can develop in the university ecosystem (Hayter, et al., 2018a, 2018b; Siegel \& Wright, 2015), and to understanding how being exposed to the overall technology transfer process can enrich their educational experience. In addition, our findings contain practical implications for policy, namely an avenue for low-cost interventions that can utilize science and technology educational programs to promote scientists' engagement and support for technology transfer activities.

This paper is structured as follows; in the theoretical background, we position our study within the context of new collaborative models for technology transfer, the role of the scientists, and prior research on student entrepreneurship. The next section presents our research design, method, setting, and data. This is followed by the presentation of the results of the iterative process of data analysis. Finally, we discuss our findings and 
implications and conclude by acknowledging the limitations of this work and describing avenues for future research.

\section{Theoretical background}

In the search for broader and deeper societal impact, the technology and knowledge transfer activities become a pivotal element in the transition towards an entrepreneurial university model (Guerrero et al., 2015; Klofsten et al., 2019), where science commercialization connects scientific research with societal and economic impact (Fini, et al., 2018a, 2018b). However, a successful realization depends on a productive collaboration between the scientists and the respective support infrastructure within the university context, such as the TTO (Nilsson et al., 2010; Walter et al., 2018).

This relationship has been investigated from the perspective of the scientist and the TTO. Prior research has studied, for instance, how scientists respond to the introduction of monetary rewards to patenting (Lam, 2011), incentives to become academic entrepreneurs (Kochenkova et al., 2016), or the acknowledgment of industry-related activities in promotion assessments (Fini, et al., 2018a, 2018b; Walter et al., 2018). From the TTO perspective, researchers have, amongst others, explored how their organizational setup and support would influence scientists' behavior (Meoli \& Vismara, 2016), or how a TTO's visibility (or the lack thereof) explains why scientists might bypass them in commercialization efforts (Huyghe et al., 2016).

At the core of these discussions is the call to assess how TTO organization and objectives contribute to the university's goals (Fitzgerald \& Cunningham, 2016), to identify whether the TTO business model fits with the specific context and ambitions (Baglieri et al., 2018), and to provide an answer to how the TTO's competencies complement the scientists' weaknesses in research commercialization (Rasmussen \& Wright, 2015). In their review of TTO models, Bradley et al. (2013) suggest that the existing literature at the time mostly describes a traditional model where the TTO is a gatekeeper of technology transfer activities, following a patent-centric linear sequence of activities. They propose to consider a collaborative model instead, where the front-end is open for (formal and informal) interactions involving scientists and other university actors, and where the back-end is organized as a response to the specific needs of the potential technology-market application combinations (including the patent-centric approach).

\subsection{Reducing individual barriers to technology transfer}

Part of the ambition of the collaborative model is to downsize the initial burden to enter a technology transfer process. Scholars have accumulated evidence of the positive impact that informal interactions have to trigger engagement with the broader academic ecosystem beyond scientists' teaching and research responsibilities (Azagra-Caro et al., 2017; Hayter, et al., 2018a, 2018b; Perkmann et al., 2013). As a result, the focus of attention is not that much on the internal (and formalized) procedures of the TTO, but rather on how to increase the supply of research commercialization ideas. In other words, special attention is paid to increase the level of activity in the pre-invention disclosure phase.

A substantial part of scientific research with commercial potential never enters the technology transfer process (Bercovitz \& Feldman, 2008; Thursby et al., 2001). This is 
primarily due to individual choices of the scientist (Thursby et al., 2001) motivated by (1) an unwillingness to allocate time to applied R\&D activities, (2) concerns about research publication delays, (3) negative perception of commercial activities, or (4) negative perceptions of the TTO's capabilities.

In addition, there are underlying factors such as the presence (or absence) of a personal network that connects the scientists with the industry's problems, or the scientists' selfefficacy perception in relation to activities related to academic entrepreneurship or technology transfer in general (Foo et al., 2016). Therefore, such activities require a rather pathdependent behavior (Thune \& Gulbrandsen, 2014) that is difficult to trigger (Bienkowska $\&$ Klofsten, 2012). Furthermore, there are self-reinforcing mechanisms, for instance the presence of peers or role models in the same department (Bercovitz \& Feldman, 2008; Foo et al., 2016) or a supportive (towards research commercialization) department head/chair, that contribute to the creation of an organizational climate that promotes such proactive behavior (Aldridge et al., 2014; Greven et al., 2020; Hottenrott \& Lawson, 2017).

Altogether, prior research suggests a connection between successful initiation of technology transfer activities and a reduction of individual barriers. Considering the individual reinforcing mechanisms and the dependence on a supportive organizational climate, the missing element is a spark that could trigger an initial positive experience in technology transfer activities. Given that the challenge for some of the scientists is to have this first collaboration with an outside actor (Thune \& Gulbrandsen, 2014), an option could be to search for this spark inside the university context.

\subsection{The role of students and educational programs in technology transfer}

Inside the university context, students have received increasing research attention to further explain their contribution to technology and knowledge transfer activities (Hayter et al., 2017). This is primarily due to the fact that past research observed that the students' role is more significant than previously expected (Siegel \& Wright, 2015).

First and foremost, researchers have observed that recent university graduates are more likely to start a business than university faculty, and with substantial and direct economic impact (Acs et al., 2016; Åstebro et al., 2012). But it is not only recent graduates that contribute to transfer internal knowledge to society; current students can also play a substantial role. $\mathrm{PhD}$ students and post-docs can contribute to the establishment of academic spin-offs, helping to initiate new venture creation processes or even assuming a role as co-founders (Hayter et al., 2017). The more exposed they are to industry partners during their $\mathrm{PhD}$, the more likely they also engage in entrepreneurial activities afterwards (Bienkowska et al., 2016).

Second, students are also an indirect driver of knowledge and technology transfer. Students often take the role of a bridge between academic and industry contexts, as they can help to start informal and formal activities with firms (Löfsten et al., 2020) and effectively establish a first contact with relevant industry that could lead to a positive impact on research and valorization activities (Galán-Muros \& Plewa, 2016). In addition, students, in contrast to research-focused scientists, see a reputational value in their engagement with industry (Huszár et al., 2015) as it provides them with practical insights and potential future career opportunities.

Finally, most of the interaction between scientists and students occurs in the context of students' educational programs. Thus, such programs can provide an ideal context to activate university-industry collaborations that might lead to technology transfer initiatives 
(Kunttu, 2017). However, while entrepreneurial education programs have become popular in disciplines like business and management, the a priori high potential STEM programs have only recently started to adopt such courses in their curriculum (Kleine et al., 2019; Piperopoulos \& Dimov, 2015; Snihur et al., 2021). In this direction, the introduction of technology commercialization education (Barr et al., 2009), technology entrepreneurship (Kleine, 2020), or more generic entrepreneurship education programs for technical and engineering students (Secundo et al., 2016; Snihur et al., 2021) are a promising avenue to generate the much-needed connection between scientists and students educational goals with a potential contribution to the universities' technology transfer (Bolzani et al., 2021).

While the contribution of students in the later stages of technology transfer as student entrepreneurs (Åstebro et al., 2012), co-owners of spin-offs (Boh et al., 2016; Hayter et al., 2017), or surrogate entrepreneurs (Würmseher, 2017) is increasingly visible, less is known about how they can participate, as part of their educational programs, in triggering scientists' interest to search for market applications and to engage in the early stages of the technology transfer process.

As a result of these insights, we propose to explore the following research question: how do students contribute, through an educational program, to the initiation of scientists' technology transfer processes? Taking the theoretical background into account, we pay special attention to the knowledge and perspectives exchanges that can potentially contribute to both the students' and the scientist's learning in relation to technology transfer.

\section{Research design}

\subsection{Method and research setting}

Given the limited theorizing and empirical evidence regarding our specific research question, we employ an inductive longitudinal multi case theory-building design (Eisenhardt $\&$ Graebner, 2007). This approach also fits with the process-focus we assume to study the phenomenon and how it evolves over time (Gehman et al., 2017; Langley et al., 2013; Van de Ven \& Poole, 2005). We use an embedded design to explore the effects of the differences in individual scientist profiles and technology types in a homogeneous context, in line with similar studies (see Knockaert et al., (2011)) and multiple case research design guidelines (Eisenhardt \& Graebner, 2007; Gehman et al., 2017). The design also aims to respond to the call for more in-depth and rigorous qualitative studies in technology transfer research (Cunningham et al., 2017).

Our setting is an engineering master's course (semester project) at a science and technology institute. The institute is part of a multi-campus university and its research focus is on nanotechnology and mechatronics. The institute hosts several advanced research groups and educational programs. The course is designed to expose students to technology entrepreneurship and innovation challenges and opportunities. The students-scientist collaboration was formalized as follows: (1) an invitation was shared with the institutes' scientists to participate in the course, (2) the scientists prepared a short pitch (and a short written proposal) describing a promising technology or research they had been working on, (3) the students were informed of the possible projects and they self-organized in groups, (4) in an open voting process they selected a project (and scientific partner) after hearing the scientist's pitch. 
This kick-off was followed by a 5 months collaborative project. The course contents followed a similar approach to those used in the NSF I-Corps (Huang-Saad et al., 2016) and the market opportunity navigator (Gruber \& Tal, 2017). The final deliverable of the course was a short business case presentation of the technology-in-use. The course had mandatory intermediate deliverables (organized as milestone reports), guidelines on the importance of weekly updates (short meetings) between the scientist and the students, and checkpoints were the scientist and students can exchange viewpoints and adjust the project development.

\subsection{Case study selection and data collection}

We applied theoretical sampling of our cases in an embedded multi case study approach (Eisenhardt \& Graebner, 2007; Gehman et al., 2017). We did so as we were able to select from the different responses that were received from the scientists in the institute, where we invited those that a priori would contribute to clarifying the effects of the different sources of expected heterogeneity to participate in the course. The sources of expected heterogeneity were differences in the technology maturity and the scientists' profile; meanwhile we kept the other potentially influencing factors as homogeneous as possible: research context (institute \& university objectives and incentives), geographical setting (campus environment), and students' profiles (engineering).

Prior research has identified that both the technology value maturity and the characteristics of the scientists (status, reputation, experience, etc.) can be influencing factors on (a) how they approach the technology transfer process (Azagra-Caro \& Llopis, 2018; Perkmann et al., 2013), and (b) the likelihood of successful commercialization (Kirchberger $\&$ Pohl, 2016). We used academic status (position) to select among scientist characteristics. To differentiate between technologies we used the concept of the technology readiness level (TRL), as adopted by Mankins (2009). We acknowledge the critique that the perception of technology readiness is highly dependent on organizational specifics (Heslop et al., 2001) and that it is difficult to precisely determine the commercialization potential of early-stage technologies (Galbraith et al., 2010). Nonetheless, we use the TRL terminology as it allows for cross-case comparisons. The TRL describes the functional maturity of technology from basic discipline research (TRL 1) to system test, deployment, and operations (TRL 9). The maturity levels of the technologies brought by the scientists under study are in the mid-maturity levels: research to prove feasibility, and technology demonstration levels (TRL 3-6). In this study, the TRL level was determined by the scientist and validated by the researcher collecting the cases. The four different cases that were finally selected and studied are presented in Table 1.

During the five months of the project, we collected data at three points. At the beginning of the project, we collected the scientists' pitch document, their academic CV, and their initial technology application idea (if any). Halfway, we conducted semi-structured interviews with the student teams and individual interviews with the scientists. At the end of the project, we again interviewed the scientists and contrasted their insights (to increase data validity and reduce qualia) with the student team's reflection reports and interview data, following the standard procedures of data triangulation to increase accuracy (Hallen \& Eisenhardt, 2012).

The 16 semi-structured interviews (three with each scientist, one with each student team) lasted between 16 and $39 \mathrm{~min}$. In each interview, we covered the status of the project 


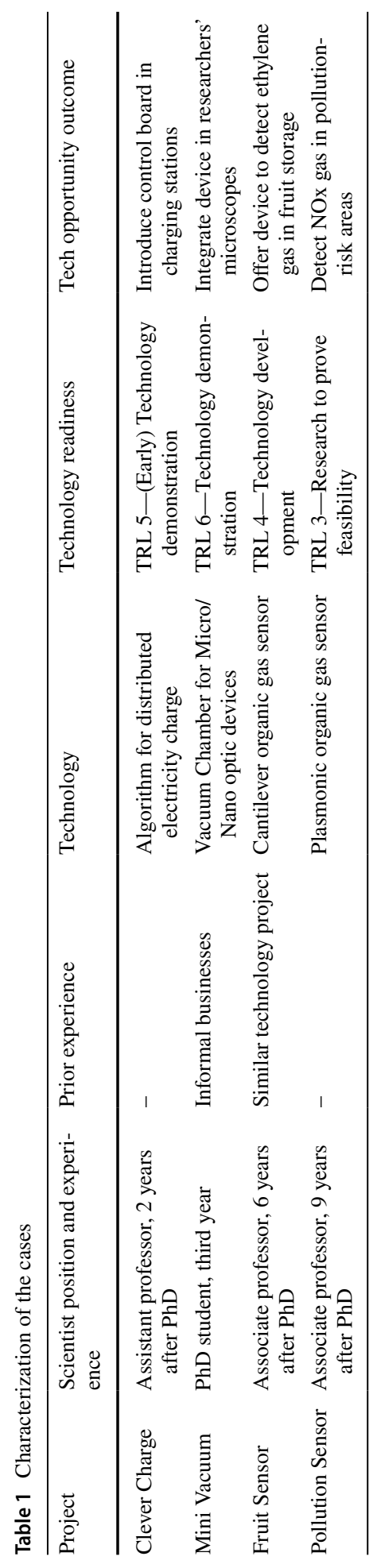


(including the market and technology situation), the ongoing challenges and opportunities, the learnings (positive and negative experiences), as well as the plans for the next steps. All interviews were transcribed. Together with the idea pitches, the project group reports, and the individual reflections, this resulted in a total of approximately 54,000 words as data corpus, distributed across the four case studies.

\subsection{Data analysis}

Applying theory-building data analysis techniques according to Eisenhardt (1989), we first completed a within-case analysis and then turned to a cross-case analysis to identify similar themes across the multiple cases (using NVivo 12). Our initial focus (following our research question) was on understanding the students' contribution to the scientist's technology transfer intentions and awareness. In the within-case analysis we identified that this contribution was evolving as the project advanced. This guided our first analysis round to establish whether we observed changes in the relationship between the students and the teams during the duration of the project. As we identified a similar pattern across the projects, we compared our findings with prior research, which supported us to characterize each of the different stages (specify the dimensions that characterize them).

At this point, we shifted our focus to the cross-case comparison and we revisited the case data to decipher the mechanisms that drive the change between the stages. Again, we iterated our emerging theoretical insights (findings) with prior research to refine and consolidate them. Three researchers revised the quotes and coding and, in doing so, systematically developed the final themes and propositions (presented as findings) through intense dialogue. Next to the triangulation of the data, this assured reliability of the data analysis. Once we had correspondence between the data, the theoretical insights (constructs and mechanisms), and prior research, we diagramed and finalized our explanatory framework (process model).

\section{Results}

We organize our results in two parts. First, we describe the process stages that emerged through the within-case analysis and that were then validated in the cross-case analysis. Second, we elucidate, in more detail, the mechanisms (as findings) that capture how the interactions between technology, market, and scientist's drove this collaboration process back and forth.

\subsection{A process-view on building the technology transfer opportunity}

To discern across the different stages, we observed three dimensions that, based on prior literature, would be potential sources of heterogeneity: (a) the technology development, (b) the technology-market combination, and (c) the collaboration relationship between the scientist and the students. In line with prior studies on how nascent technologies are converted into innovations, and how this depends on the level of uncertainty regarding the capabilities of the technology (Woolley, 2014), we used the technology development (maturity) 


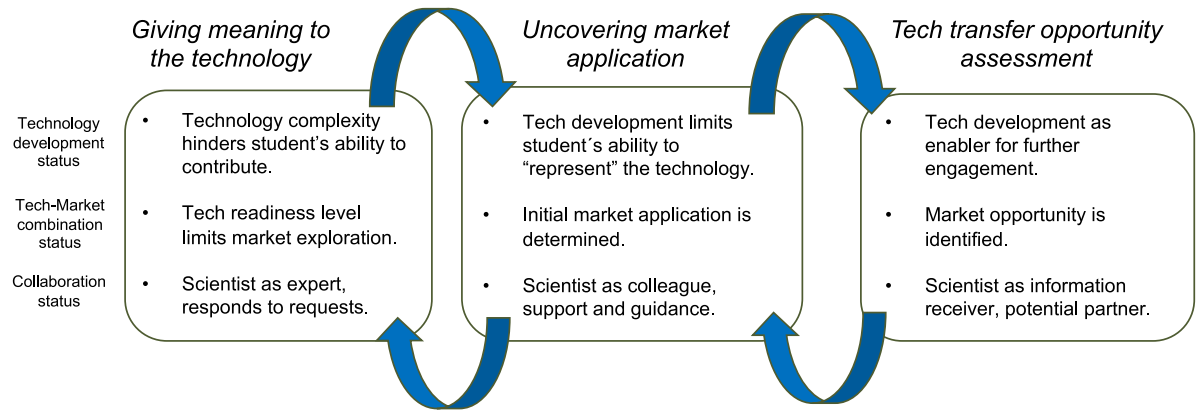

Fig. 1 Stages in the process of building a technology transfer opportunity

dimension to help us differentiate the process stages. The distance between the technology features and a market "problem" captures whether there is a technology-market combination and how solid it is (Gregoire \& Shepherd, 2012; Gruber et al., 2008). We used the extant work on this topic to help us further characterize each stage. Finally, we identified a correspondence between our data and prior research that described how social and cognitive proximity is seen as an enabler for university-industry collaboration (Steinmo \& Rasmussen, 2018; Villani et al., 2017). This last dimension helped to capture how the relationship between the students and the scientist was influencing (and being influenced) by their knowledge exchanges. Taken together, the three dimensions contribute to characterize each of the proposed stages (see Fig. 1).

The first stage, Giving meaning to the technology captures the initial challenge that the scientist encounters when working with the students. The scientist needs to find a meaning for the technology, reframing the value of prior research (his prior knowledge) or technology development into a potential market application. Prior research has identified that this is a key challenge in the search for applications beyond the scope of an individual's prior knowledge (Gruber et al., 2013). This generates an initial tension; the students express their need to know what the technology "means": "our questions to her were purely (mostly) with respect to the technology and how it will work" (fruit Sensor-student group). However, from the scientist's viewpoint this requires effort to find explanations and meanings: "for them (students) it is tricky to actually grasp, get the core, essence of what we are trying to do (in research)" (Clever Charge-scientist).

At this stage, a low TRL makes it cumbersome for students to relate to the technology and the possible applications. Further, advanced technologies, such as new plasmonics approaches to develop nano-sensors (as used in the fruit sensor or pollution sensor), require an initial understanding of the chemical and physical theories behind the technology (Table 2). The scientist adopts the role of an expert researcher of the technology and tries to bring the student group up to speed, guiding them through the key principles that need to be understood to find possible meanings, making sense of the technology features and possible benefits. This helps the scientist to find a meaning for the technology beyond the specifics of the research behind it. Additional quotes to illustrate this stage and the subsequent stages can be seen in Table 3 .

The second stage, Uncovering the market application, describes the identification of possible market applications for the technology. Prior research highlights that the establishment of a technology-market combination has a significant impact on the formation of opportunity beliefs (Gregoire \& Shepherd, 2012), and thus can be a driver of further action (Mitchell et al., 2008). This means that the students' contribution is to "find the 
Table 2 Data sources

\begin{tabular}{ll}
\hline Interviews (transcribed and coded) & Other documents \\
\hline $\begin{array}{l}\text { Initial interviews with the scientist to identify the } \\
\text { technology (4 with a duration between } 16 \text { and }\end{array}$ & $\begin{array}{c}\text { Idea pitch by scientist (1 pager)_-(4 idea pitches of } \\
\text { max. } 1000 \text { words each) } \\
\text { Project reports (milestones and final deliverables) } \\
\text { and students' individual reflections (4 reports of } \\
\text { over 20 pages each) }\end{array}$ \\
$\begin{array}{l}\text { Follow-up interviews with the scientists (4 with a } \\
\text { duration between } 19 \text { and } 25 \text { min). Beginning of the } \\
\text { project }\end{array}$ & $\begin{array}{c}\text { Scientists' profiles (CV) } \\
\text { Mid-project interviews with students' teams (4 with a } \\
\text { duration between } 21 \text { and } 32 \text { min) }\end{array}$ \\
$\begin{array}{l}\text { Final interviews with scientists (4 with a duration } \\
\text { between } 26 \text { and } 39 \text { min). End of the project }\end{array}$ & \\
\end{tabular}

Table 3 Illustrative quotes used in the identification of stages in the building of technology transfer opportunities

\section{S1: Giving meaning to the technology}

We have just faced challenges at the starting point because we didn't have so much technical knowledge

First, our questions to her were purely with respect to the technology and how it will work. Asking every question, we come across related to the project from the technology point of view

For them [the students] sometimes it is tricky to ask actually, grasp, get the core, essence of what we are trying to do [technology-wise], but that is also because this technical field is really, really difficult

\section{S2: Uncovering market application}

We improved the technology more and more, but the companies are not really interested in that. So, we thought first we have to identify who is the customer, what kind of things they want into that and then we will upgrade the product

Our contribution has been mainly finding the potential customers

This is really an idea that you can commercialize, but it is hard to say that if I do not have an overview of the market. And that is what they [the students] are trying to do right now

\section{S3: Technology transfer opportunity assessment}

We improved the technology more and more, but the companies are not really interested in that. So, we thought first we have to identify who is the customer, what kind of things they want into that and then we will upgrade the product

(my objective is) To find a new direction, a new industrial direction that would be our, and then have a clear goal for future development

It would be nice to have an answer how to proceed this; should we go for this project or not? And I thought there might be a niche that is interested and would like to find out and I think they did that

Basically, we get a good overview over the potential of this commercialization idea

Now the set-up is in a better version than when we started. Pollution sensor scientist, 2nd round interviews [...] Technology readiness level is more or less the same, however now we have a base for this, now we can jump through some TRL levels much faster than before
Midterm interview (student teams)

Midterm interview (student teams)

Clever Charge scientist,

1 st round interview

Midterm interview (student teams)

Midterm interview (student teams)

Clever Charge scientist,

1 st round interview

Midterm interview (student teams)

Mini-vacuum scientist, 1st round interviews

Fruit sensor scientist, 1st round interviews

Mini-vacuum scientist, 2 nd round interviews 
potential customers" (mini-vacuum—student group), which also involves to "identify who is the customer, what kind of things they want" (pollution sensor-student group). In words of one of the scientists, it is that "overview of the market... what they (the students) are trying to do" (Clever Charge-scientist). Interestingly, as the students overcome the challenge to present the technology to potential customers or interested parties, the scientist starts shifting roles, from being only a technology expert to becoming a team colleague who offers support and guidance. In this stage the students start to accumulate market knowledge and industry interactions that are seen as potential new input for the scientist.

Finally, the third stage: Technology transfer opportunity assessment, depicts how the agreement on a potential market opportunity generates a decision option for the scientist, to either engage further in the technology transfer process or abandon the specific technology idea. This stage resonated with observations in decision-making processes were individuals have to decide whether to take the plunge or pull the plug (Bakker \& Shepherd, 2017). This final stage gave the scientist the answer to "should we go for this project or not" (fruit sensor-scientist). The identification of a market opportunity is seen as a facilitator of further technology development (and value); "now we have a base for this (the product), now we can jump through some TRL levels much faster" (pollution sensor-scientist). It is at this stage where the researcher takes a different role, receiving and processing new information: "we get a good overview of the potential of this commercialization idea" (minivacuum - scientist). Even though the focus is on the potential of the market application, the technology development status has an impact on the readiness of the opportunity and on the future expectations, for both, the scientist and the students, and consequentially on their future engagement in the technology transfer process.

The overall process has a dynamic nature; during our observation time, the projects evolved through (sometimes doing iterations backward) all stages. Thus, it is particularly valuable to better understand what drives the changes of stage. The mechanisms behind these changes are described as findings (F1 to F4) in Fig. 2. The illustrative quotes of the data that supported these findings can be seen in Table 4.

F1. The greater the consensus on the technology function, the more likely the identification of a market application.
F3. The greater the market response on the technology application, the more likely the scientist engages with the opportunity.

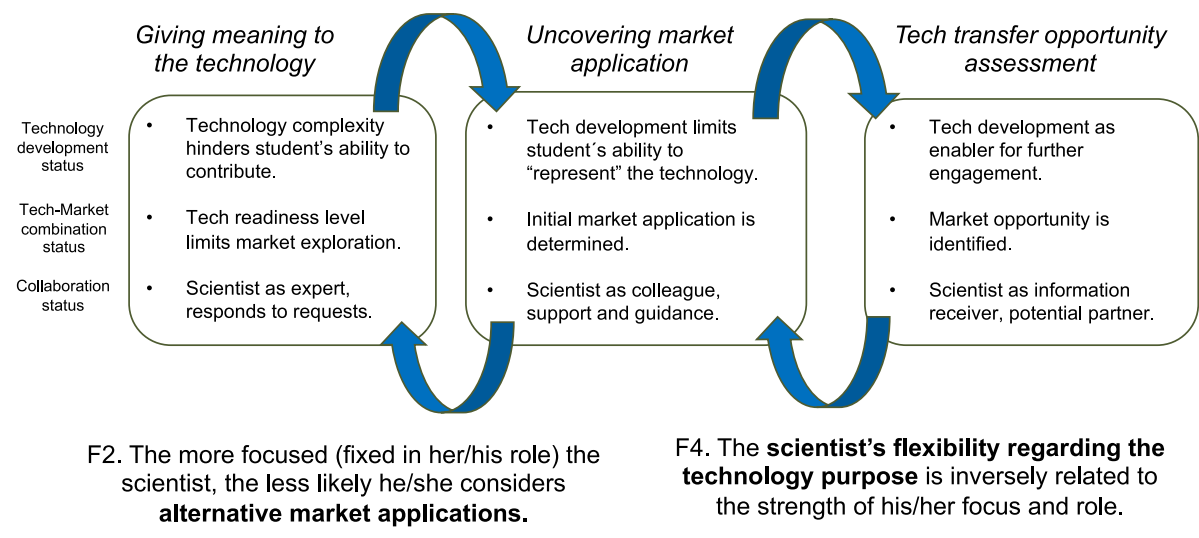

Fig. 2 Explanatory framework 
Table 4 Illustrative quotes used in the development of the findings

\section{F1: The greater the consensus on the technology function, the more likely the identification of a} market application

It would be very helpful for us if we were able to build kind of a prototype which we can take to the people to show them this is the actual way this thing is going to work

He is currently focusing more and more towards the technology. How I can improve this sensor and what features I add. And then, at the end of the day, I told him that, no, companies don't need this thing. They are more interested in sensing more and more gases from it rather sensing only one gas

It's much better when you have some kind of prototype, but a fully operational prototype. [...] it's better when you have an idea where you're able to judge, these are my limitations, my sensitivity and so on so people really have a lot of questions; [...] we are not interested until you give us some promising numbers

Midterm interview (student teams)

Midterm interview (student teams)

Pollution sensor scientist, 2nd round interviews

\section{F2: The more focused (fixed in her/his role) the scientist, the less likely he/she considers alternative market applications}

This is not exactly the device we had at the beginning, but it could be an opportunity to develop something new, but it would have to be from scratch. [...] Yes, that means we would have to research new kind of sensors which are very cheap [...], but then we would have to find out how to do that

The companies that are interested in that product, they are asking us more and more technical questions about that. That, how it works, how these sensors interpret with each other and how connects with the cloud system, what kind of advancement you can add to that process. And each and every time, we satisfy them as far as we can. Then we have to return to our mentors, or the supervisor, Jacek, and we tell them that they are asking these kinds of questions

They are not helping development in the lab, but we are not thinking about marketing [...], so whatever they are doing, it's helpful for us. Even if it's people who are not interested in this, is helpful because we can decide to follow another path

Fruit sensor scientist, 2nd round interviews

F3: The greater the market response on the technology application, the more likely the scientist engages with the opportunity

He said we need to make it smaller and lighter and you don't need a heating or cooling system, but then there is a market and we can sell it for way less than like competitors which are selling it for $70.000 €$ and we were like, that sounds good, that's sound good, so we started and then we realized ok, it's not that easy

In our research phase we say, ok we develop something and now we are ready to go outside the lab, so any door will be open for us, it is ok

If we have a market, then we can really think about starting some small company, probably in collaboration with the workshop, and to make few prototypes, to make few products

Pollution sensor scientist, 1st round interviews

Mini-vacuum scientist, 1st round interviews 
Table 4 (continued)

F4: The scientist's flexibility regarding the technology purpose is inversely related to the strength of his/her focus and role

Our project is very open-ended, this is the technology, and Fruit sensor scientist, 1st round interviews it is up to you on how we are finalizing this, it should work with many different gases and this is not a problem

Our technology, or how to say, we are developing many different components that could at the end be assembled together in one sensing system. So, depending on the market requirements, whenever we talk to somebody from the industry and they say that they have a different need, we can still use some of these elements, some of the components, and then we can build completely different sensor

We had a lot of discussions; we got a lot of feedback and input and there was also sort of a product development during the phase of this project. [...] The product was actually refined because of the feedback and what the students did

This is not exactly the device we had at the beginning, but it could be an opportunity to develop something new, but it would have to be from scratch. [...] Yes, that means we would have to research new kind of sensors which are very cheap [...], but then we would have to find out how to do that

Pollution sensor scientist, 1st round interviews

Pollution sensor scientist, 2nd round interviews

Fruit sensor scientist, 2nd round interviews

\subsection{From giving meaning to the technology to uncovering a market application}

At the first stage of the process, the challenge is to uncover how the technology works and what possible functions it can have. Thus, a requirement for further action is to narrow down the possible functions of the technology. One student group expressed this as the need to "build a kind of a prototype which we can take to the people to show this is the actual way this is going to work" (pollution sensor-students). This creates an apparent paradox as feedback is needed to guide the technology development, but to get feedback there needs to be an agreement on a plausible function to create the first prototype. As one of the scientists stated, there is a need for "a fully operational prototype...it is better when you have an idea ... you are able to judge" (pollution sensor-scientist). Yet again, this requires an initial consensus on a technology function. Therefore, we suggest that:

Finding 1: The greater the consensus on the technology function, the more likely the identification of a market application.

During this stage, we observe that the expectations of the scientist and his/her openness to consider possible alternative functions, influence the likelihood of a transition towards uncovering a possible market application. While some scientists have a fixed idea regarding their role in the collaboration and the distinctive features of the technology, others are open to emerging ideas or possibilities. To move the process ahead, it often means to be open to "an opportunity to develop something new" even if it "has to be from scratch" (fruit sensor - scientist). This triggers a change in the scientist's role in the collaboration, namely, from being an expert to becoming a colleague (or peer) in the students' team. For instance, one of the scientists was explicitly describing that 
"even if people are not interested in this (the scientist's initial technology application idea), it is helpful (to get negative feedback), because we can decide to follow another path (pollution sensor-scientist). As a result, we argue that:

Finding 2: The more focused (fixed in her/his role and ideas) the scientist, the less likely he/she considers alternative market applications.

\subsection{From a market application to a technology transfer opportunity}

The connection between the second and third stage requires the consolidation of a possible market opportunity and a closer understanding of the current status of the technology and its plausible future development. Interestingly, almost any type of market response (even if somewhat negative) increases the interest of both students and scientists. New insights can be seen as obstacles but also opportunities: "if we make it smaller and lighter...then there is a market... and we can sell it for less than competitors...that sounds good, so we started and then we realized, ok, it is not that easy" (mini-vacuum, students), or from the scientist viewpoint: "we can really think about to start some small company, probably in collaboration with the workshop, and to make a few prototypes" (mini-vacuum, scientist). The realization that the technology has a potential application often comes as a positive surprise to the scientist. The students help to uncover new information on the market structure and demands, often also proposing applications that were not considered a priori. Therefore, we propose that:

Finding 3: The greater the market response on the technology application, the more likely the scientist engages with the opportunity.

However, the exploratory nature of the process might clash with the pre-established ideas that the scientist has regarding the uses of the technology. This potential setback is different from the one observed between stages 1 and 2 . It challenges the actual contribution of the technology for a specific market application. This generated for instance a tension in the Clever Charge team, where the scientist and students' team could not agree on whether the advantage of the technology was a part of an existing solution, or as a standalone product. In other cases, this did not occur as a problem: "whenever we talk to somebody from the industry and they say that they have a different need...then we can build a completely different sensor" (pollution sensor-scientist). There is a difference in whether the scientist sees the potential outcome as a single, unique project that maximizes the potential of the technology, or whether the scientist views this as one initial project that could be followed by others "our project is very open-ended, this is the technology (advanced sensor) and it is up to you how we are finalizing this" (fruit sensor-scientist). As a result, we argue that:

Finding 4: The scientist's flexibility regarding the technology purpose is inversely related to the strength of his/her focus and role.

The combination of the process model and the mechanisms, described as findings, result in the explanatory framework presented in Fig. 2. 


\section{Discussion and implications}

In the context of a university, the decision to disclose an invention constitutes the beginning of formal technology transfer activities (Walter et al., 2018). Much of prior research has focused on what happens after the invention disclosure to the TTO (Baglieri et al., 2018). However, the motivations of the researchers to engage with the market are often more complex and not that easy to observe (D'Este \& Perkmann, 2011). Similarly, prior research of student entrepreneurship and of students in academic entrepreneurship focused on new ventures by graduated students, or on the creation of academic spinoffs (Åstebro et al., 2012; Hayter et al., 2017). Taking the viewpoint of the scientist, we propose to take a step backward and explore the potential contributions of students in the pre-invention disclosure phase, when the scientist is still unsure of the technology application and lacks experience and support to start the technology transfer process. By studying four cases of students-scientist collaboration projects, as part of an educational program, we propose an explanatory framework and theoretical insights regarding how the process evolves from an initial research-based idea to a potential technology transfer opportunity.

\subsection{Students as co-pilots in the first steps towards scientists' technology transfer activities}

In our findings, we observe that for projects with low TRLs the contribution of the students is stronger when the researcher has a rather flexible and open perspective regarding the possible applications of the technology. This requires the ability to adjust and change paths from the scientist, to consider alternatives, and to reevaluate choices. This is a rather individual cognitive process strongly influenced by the mental model of the actor (Gary \& Wood, 2011; Johnson-Laird, 1980). In this setting, the scientists' mental models influence their ability to use new information available to change (or sustain) their behavior and expectations regarding the technology transfer process. This challenges the often dominant logics in the research context where specialization, persistence, and narrow focus pays off (Kotha et al., 2013). For the students to be co-pilots, the scientist needs to also offer some degree of flexibility regarding which direction to go.

In our cases, it became clear that projects with higher TRLs meant that the researcher had already invested significant efforts in the development of the technology and might have built a preconception on what is a suitable business application or market for his/her technology. Nevertheless, a higher TRL facilitates a quicker understanding of the technology and motivates the students to have a "boundary spanner" function (Mangematin et al., 2014). This results in further engagement of the scientist as long as there is a consensus on the technology function, as it has also been observed with technology evaluation panels (Galbraith et al., 2010), where the shared consensus becomes a driver of further action among the process stakeholders.

Thus, we contribute by identifying a possible setup to open up the onset of the technology transfer process, in line with the suggestions to consider collaborative models (Bradley et al., 2013) into which additional stakeholders get involved or take different roles as part of an emerging academic ecosystem (Hayter, et al., 2018a, 2018b). In addition, we suggest an additional role for students and propose a collaborative model to reduce entry barriers for scientists that consider to engage in technology transfer activities. 


\subsection{A two-way learning process in the onset of the technology transfer process}

Taking part in such a collaborative process for technology transfer is also likely to render positive impacts for the different stakeholders. The scientist, depending on his/her flexibility and openness, acquires new information and knowledge about a potential market application for the technology. The collaborative process offers an experience in a limitedrisk context (safer than launching an academic spin-off) where a potential negative (or null) outcome of the collaboration does not damage the scientist's reputation or academic status (Lam, 2011).

Our findings also contribute to a better understanding of why some research ideas never make it to the invention disclosure stage (Thursby et al., 2001) by suggesting the need for external input or interventions that change the path, or provide the necessary support to advance to a stage where it is more reasonable to take the plunge (Bakker \& Shepherd, 2017) and enter the formal technology transfer process in the university.

The students' learning is an essential counterpart in our framework. The development of technology commercialization competences has been an area of growing interest in the educational programs in science and technology fields (Barr et al., 2009; Nelson \& Monsen, 2014). Our findings contribute to this ongoing conversation on how TTO's traditional activities can become part of the educational programs (Bolzani et al., 2021), and how the TTO can also benefit from opening up their function to university ecosystem actors (Giuri et al., 2019). The different stages we identified, and the interaction dynamics between the scientist and the students' team, support the encouraging evidence found in similar educational initiatives were using business modeling tools or market exploration tools contribute to building entrepreneurial mindset skills in engineering students (Gruber \& Tal, 2017; Snihur et al., 2021).

Finally, our findings also provide evidence of the potential theorizing benefits from introducing insights from entrepreneurship research in the study of the ideation or initial opportunity development of the technology transfer process. The parallelisms between the figure of the entrepreneur considering an opportunity, and a scientist considering a technology application opportunity, allowed to enrich our findings with insights from entrepreneurial decision-making on how technology-market combinations could be assessed as potential technology transfer opportunities (Bakker \& Shepherd, 2017; Gregoire \& Shepherd, 2012).

\subsection{Practical implications for technology transfer and policy}

While the notion that TTOs need to find the right business model depending on the context they operate in (Baglieri et al., 2018) is difficult to dispute, it is more challenging to identify new pathways to improve the technology and knowledge transfer at universities. Based on our explanatory framework, we suggest that an option is to share part of the traditional activities of the TTO with other actors in the academic ecosystem. We believe that this can be particularly productive in settings were the TTO has limited resources or struggles to attract contributions from the scientific staff.

However, it is important to clarify that the adoption of educational arrangements like the one we studied is not absent of additional tensions and risks for the TTO. For instance, as it happens with other collaborative models for technology transfer, opening up the front-end of the process also means taking into special consideration how this type of arrangement 
can generate intellectual property rights (IPR) disputes in the future. Also, it is essential to connect the more or less informal activities with what would be the onset of the already established technology transfer activities that fall under the responsibility of the TTO.

Policymakers interested in seeing an economic and societal impact from the research activities at universities can find in our work an inspiration for a low-cost intervention in science and technology educational programs. Nevertheless, this would be a precipitated shortcut. First, while students would benefit from the experiential learning of being engaged in technology transfer projects with scientists, the project still has to be designed and managed to ensure the course learning outcomes. And second, the collaborative experience we studied provides a small spark to scientists that already have an initial consideration for technology transfer opportunities; it does not replace the much-needed support, in particular for younger scientists, to build connections beyond the university boundaries and to help them generate scientific and societal impact.

\section{Conclusions}

In response to the increasing interest to identify alternative (Hayter, et al., 2018a, 2018b) or collaborative (Bradley et al., 2013) models for technology transfer, we studied the learning dynamics between students and scientists in the preliminary commercial exploration of promising research. Using as context a five months semester project, part of a master's educational program in a university, we analyzed four technology exploration projects in an embedded multiple-case study. Our data suggest distinct stages of evolution and driving mechanisms that explain what made the collaborative project go forward or backward.

We contribute by introducing technology-meaning consensus between the scientist and the students, as a spur to move the potential technology transfer projects forward. Nevertheless, we also identify that the rigidity of the scientist's focus and perceptions can be an obstacle to the exploration and possible identification of technology-market combinations. Paradoxically, this implies that engaging in this collaborative process with a well-defined idea on the new technology application could be counterproductive for the scientists. But simultaneously, too open and vague ideas regarding the possible functions or uses of the technology limit student's engagement in the project onboarding.

This implies that technology transfer office managers could consider the participation in educational activities that promote collaboration between students and scientists, in particular in the stages before the traditional formal steps of the technology transfer process (i.e. invention disclosure). Such collaborations could open the door to redefining actors' roles (in this case students) in the technology transfer process, while also providing valuable learning experiences for both the students and the scientists.

We acknowledge the boundaries and limitations of our study. First, although we conducted several interview rounds and complemented our interview data with additional sources, we did not measure or capture in detail how the perceptions or attitudes of the scientists would change as a response to project setbacks or positive updates. Further research could explore how the scientists' perceptions of technology transfer change across time, and how the individual or contextual aspects influence how they process, absorb, and respond to such unexpected events. In this vein, we identified that the scientist's mental model could be a source of explanation for the different behaviors we observed. Further research could measure the fixation (or confidence) of the scientist in their judgment of the different market applications and then study to what extent the strength of their mental 
model impacts the likelihood of identifying a technology transfer opportunity that could be exploited in the future.

Second, we focus on the preliminary steps of the technology transfer process, leaving the opportunity for further research to explore similar arrangements in later stages of the technology transfer process. Such arrangements could equally generate learning opportunities for students. However, it would be crucial that they are considered in light of the students' education and learning goals.

Third, it would be interesting to explore experiments that would combine different types of technologies, researchers, and student profiles (for instance, including business students). This could help to uncover the combinations that have additional effects or factors that went unnoticed in our research design. For example, further research could explore aspects related to cognitive diversity at the team level, exploring some of the emerging findings from other research fields in the context of technology transfer opportunities (Wiklund et al., 2018).

Finally, it would be particularly interesting to study the long-term effects of participating in such types of collaborations. For instance, exploring the effect on scientists' perceptions and intentions to engage with the industry or other technology transfer projects that involve external actors. Similarly, following up on the students' career choices could also help to decipher the long-term impact of being engaged in such collaborative experiences with scientists.

Acknowledgements We thank the editors and the anonymous reviewers for their guidance, comments, and suggestions. We are also grateful to participants of the T2S Conference (2018), the Ingenio (CSIC-UPV) and ERPI-University of Lorraine research seminars, and in particular to Chris Hayter for their valuable feedback to previous versions of this work.

Funding Open Access funding enabled and organized by Projekt DEAL.

Open Access This article is licensed under a Creative Commons Attribution 4.0 International License, which permits use, sharing, adaptation, distribution and reproduction in any medium or format, as long as you give appropriate credit to the original author(s) and the source, provide a link to the Creative Commons licence, and indicate if changes were made. The images or other third party material in this article are included in the article's Creative Commons licence, unless indicated otherwise in a credit line to the material. If material is not included in the article's Creative Commons licence and your intended use is not permitted by statutory regulation or exceeds the permitted use, you will need to obtain permission directly from the copyright holder. To view a copy of this licence, visit http://creativecommons.org/licenses/by/4.0/.

\section{References}

Acs, Z., Åstebro, T., Audretsch, D., \& Robinson, D. T. (2016). Public policy to promote entrepreneurship: A call to arms. Small Business Economics, 47(1), 35-51. https://doi.org/10.1007/s11187-016-9712-2

Aldridge, T. T., Audretsch, D., Desai, S., \& Nadella, V. (2014). Scientist entrepreneurship across scientific fields. The Journal of Technology Transfer, 39(6), 819-835. https://doi.org/10.1007/ s10961-014-9339-X

Alexander, A., Martin, D. P., Manolchev, C., \& Miller, K. (2018). University-industry collaboration: Using meta-rules to overcome barriers to knowledge transfer. Journal of Technology Transfer, 0123456789, 1-22. https://doi.org/10.1007/s10961-018-9685-1

Åstebro, T., Bazzazian, N., \& Braguinsky, S. (2012). Startups by recent university graduates and their faculty: Implications for university entrepreneurship policy. Research Policy, 41(4), 663-677. https://doi. org/10.1016/j.respol.2012.01.004 
Azagra-Caro, J. M., Barberá-Tomás, D., Edwards-Schachter, M., \& Tur, E. M. (2017). Dynamic interactions between university-industry knowledge transfer channels: A case study of the most highly cited academic patent. Research Policy, 46(2), 463-474. https://doi.org/10.1016/j.respol.2016.11.011

Azagra-Caro, J. M., \& Llopis, O. (2018). Who do you care about? Scientists' personality traits and perceived impact on beneficiaries. $R \& D$ Management, 48(5), 566-579. https://doi.org/10.1111/radm. 12308

Baglieri, D., Baldi, F., \& Tucci, C. L. (2018). University technology transfer office business models: One size does not fit all. Technovation, (April). https://doi.org/10.1016/j.technovation.2018.05.003

Bakker, R. M., \& Shepherd, D. A. (2017). Pull the plug or take the plunge: Multiple opportunities and the speed of venturing decisions in the Australian Mining Industry. Academy of Management Journal, 60(1), 130-155. https://doi.org/10.5465/amj.2013.1165

Barr, S., Baker, T., Markham, S., \& Kingon, A. (2009). Bridging the valley of death: Lessons learned from 14 years of commercialization of technology education. Academy of Management Learning \& Education, 8(3), 370-388.

Bercovitz, J., \& Feldman, M. (2008). Academic entrepreneurs: Organizational change at the individual level. Organization Science, 19(1), 69-89. https://doi.org/10.1287/orsc.1070.0295

Bienkowska, D., \& Klofsten, M. (2012). Creating entrepreneurial networks: Academic entrepreneurship, mobility and collaboration during $\mathrm{PhD}$ education. Higher Education, 64(2), 207-222. https://doi.org/ 10.1007/s10734-011-9488-x

Bienkowska, D., Klofsten, M., \& Rasmussen, E. (2016). PhD Students in the Entrepreneurial University: Perceived support for academic entrepreneurship. European Journal of Education, 51(1), 56-72. https://doi.org/10.1111/ejed.12160

Boh, W. F., De-Haan, U., \& Strom, R. (2016). University technology transfer through entrepreneurship: Faculty and students in spinoffs. The Journal of Technology Transfer, 41(4), 661-669. https://doi.org/ 10.1007/s10961-015-9399-6

Bolzani, D., Munari, F., Rasmussen, E., \& Toschi, L. (2021). Technology transfer offices as providers of science and technology entrepreneurship education. The Journal of Technology Transfer, 46(2), 335-365. https://doi.org/10.1007/s10961-020-09788-4

Bradley, S. R., Hayter, C. S., \& Link, A. N. (2013). Models and Methods of University Technology transfer. Foundations and Trends $®$ in Entrepreneurship, 9(6), 571-650. https://doi.org/10.1561/0300000048

Casati, A., \& Genet, C. (2014). Principal investigators as scientific entrepreneurs. The Journal of Technology Transfer, 39(1), 11-32. https://doi.org/10.1007/s10961-012-9275-6

Cunningham, J. A., Menter, M., \& Young, C. (2017). A review of qualitative case methods trends and themes used in technology transfer research. Journal of Technology Transfer, 42(4), 923-956. https:// doi.org/10.1007/s10961-016-9491-6

D'Este, P., \& Perkmann, M. (2011). Why do academics engage with industry? The entrepreneurial university and individual motivations. The Journal of Technology Transfer, 36(3), 316-339. https://doi.org/ 10.1007/s10961-010-9153-z

Eisenhardt, K. M. (1989). Building theories from case study research. Academy of Management Review, 14(4), 532-550. https://doi.org/10.5465/AMR.1989.4308385

Eisenhardt, K. M., \& Graebner, M. E. (2007). Theory building from cases: Opportunities and challenges. Academy of Management Journal, 50(1), 25-32. https://doi.org/10.5465/AMJ.2007.24160888

Fini, R., Jourdan, J., \& Perkmann, M. (2018a). Social valuation across multiple audiences: The interplay of ability and identity judgments. Academy of Management Journal, 61(6), 2230-2264. https://doi.org/ 10.5465/amj.2016.0661

Fini, R., Rasmussen, E., Siegel, D., \& Wiklund, J. (2018b). Rethinking the commercialization of public science: From entrepreneurial outcomes to societal impacts. Academy of Management Perspectives, 32(1), 4-20. https://doi.org/10.5465/amp.2017.0206

Fitzgerald, C., \& Cunningham, J. A. (2016). Inside the university technology transfer office: Mission statement analysis. The Journal of Technology Transfer, 41(5), 1235-1246. https://doi.org/10.1007/ s10961-015-9419-6

Foo, M. D., Knockaert, M., Chan, E. T., \& Erikson, T. (2016). The Individual Environment Nexus: Impact of promotion focus and the environment on academic scientists' entrepreneurial intentions. IEEE Transactions on Engineering Management, 63(2), 213-222. https://doi.org/10.1109/TEM.2016.25352 96

Galán-Muros, V., \& Plewa, C. (2016). What drives and inhibits university-business cooperation in Europe? A comprehensive assessement. $R$ and D Management, 46(2), 369-382. https://doi.org/10.1111/radm. 12180 
Galbraith, C. S., DeNoble, A. F., Ehrlich, S. B., \& Mesmer-Magnus, J. (2010). Review panel consensus and post-decision commercial performance: A study of early stage technologies. Journal of Technology Transfer, 35(2), 253-281. https://doi.org/10.1007/s10961-009-9122-6

Gary, M. S., \& Wood, R. E. (2011). Mental models, decision rules, and performance heterogeneity. Strategic Management Journal, 32(6), 569-594. https://doi.org/10.1002/smj.899

Gehman, J., Glaser, V. L., Eisenhardt, K. M., Gioia, D. A., Langley, A., \& Corley, K. G. (2017). Finding theory-method fit: A comparison of three qualitative approaches to theory building. Journal of Management Inquiry, 143(2), 105649261770602. https://doi.org/10.1177/1056492617706029

Giuri, P., Munari, F., Scandura, A., \& Toschi, L. (2019). The strategic orientation of universities in knowledge transfer activities. Technological Forecasting and Social Change, 138(January), 261-278. https:// doi.org/10.1016/j.techfore.2018.09.030

Gregoire, D. A., \& Shepherd, D. A. (2012). Technology-market combinations and the identification of entrepreneurial opportunities: An investigation of the opportunity-individual nexus. Academy of Management Journal, 55(4), 753-785. https://doi.org/10.5465/amj.2011.0126

Greven, A., Strese, S., \& Brettel, M. (2020). Determining scientists' academic engagement: Perceptions of academic chairs' entrepreneurial orientation and network capabilities. The Journal of Technology Transfer, 45(5), 1376-1404. https://doi.org/10.1007/s10961-019-09750-z

Gruber, M., MacMillan, I. C., \& Thompson, J. D. (2008). Look before you leap: Market opportunity identification in emerging technology firms. Management Science, 54(9), 1652-1665. https://doi.org/10. $1287 / \mathrm{mnsc} .1080 .0877$

Gruber, M., MacMillan, I. C., \& Thompson, J. D. (2013). Escaping the prior knowledge corridor: What shapes the number and variety of market opportunities identified before market entry of technology start-ups? Organization Science, 24(1), 280-300. https://doi.org/10.1287/orsc.1110.0721

Gruber, M., \& Tal, S. (2017). Where to play: 3 steps for discovering your most valuable market opportunities. FT Press /Pearson.

Guerrero, M., Cunningham, J. A., \& Urbano, D. (2015). Economic impact of entrepreneurial universities' activities: An exploratory study of the United Kingdom. Research Policy, 44(3), 748-764. https://doi.org/10.1016/j.respol.2014.10.008

Hallen, B. L., \& Eisenhardt, K. M. (2012). Catalyzing strategies and efficient tie formation: How entrepreneurial firms obtain investment ties. Academy of Management Journal, 55(1), 35-70. https://doi. org/10.5465/amj.2009.0620

Hayter, C. S., Lubynsky, R., \& Maroulis, S. (2017). Who is the academic entrepreneur? The role of graduate students in the development of university spinoffs. Journal of Technology Transfer, 42(6), 1237-1254. https://doi.org/10.1007/s10961-016-9470-y

Hayter, C. S., Nelson, A. J., Zayed, S., \& O'Connor, A. C. (2018a). Conceptualizing academic entrepreneurship ecosystems: A review, analysis and extension of the literature. The Journal of Technology Transfer, 43(4), 1039-1082. https://doi.org/10.1007/s10961-018-9657-5

Hayter, C. S., Rasmussen, E., \& Rooksby, J. H. (2018b). Beyond formal university technology transfer: Innovative pathways for knowledge exchange. The Journal of Technology Transfer. https://doi.org/ 10.1007/s10961-018-9677-1

Heslop, L. A., McGregor, E., \& Griffith, M. (2001). Development of a technology readiness assessment measure: The Cloverleaf model of technology transfer. Journal of Technology Transfer, 26(4), 369-384. https://doi.org/10.1023/A:1011139021356

Hottenrott, H., \& Lawson, C. (2017). Flying the nest: How the home department shapes researchers' career paths. Studies in Higher Education, 42(6), 1091-1109. https://doi.org/10.1080/03075079. 2015.1076782

Huang-Saad, A., Fay, J., \& Sheridan, L. (2016). Closing the divide: Accelerating technology commercialization by catalyzing the university entrepreneurial ecosystem with I-Corps ${ }^{\mathrm{TM}}$. Journal of Technology Transfer, 42(6), 1-21. https://doi.org/10.1007/s10961-016-9531-2

Huszár, S., Prónay, S., \& Buzás, N. (2015). Examining the differences between the motivations of traditional and entrepreneurial scientists. Journal of Innovation and Entrepreneurship, 5(1). https://doi. org/10.1186/s13731-016-0054-8

Huyghe, A., Knockaert, M., Piva, E., \& Wright, M. (2016). Are researchers deliberately bypassing the technology transfer office? An analysis of TTO awareness. Small Business Economics, 47(3), 589607. https://doi.org/10.1007/s11187-016-9757-2

Johnson-Laird, P. N. (1980). Mental models in cognitive science. Cognitive Science, 4(1), 71-115. https://doi.org/10.1207/s15516709 $\operatorname{cog} 0401 \_4$

Kirchberger, M. A., \& Pohl, L. (2016). Technology commercialization: A literature review of success factors and antecedents across different contexts. Journal of Technology Transfer, 41(5), 10771112. https://doi.org/10.1007/s10961-016-9486-3 
Kleine, K. (2020). Technology entrepreneurship, enriching entrepreneurship education. In Encyclopedia of educational innovation (pp. 1-5). Singapore: Springer Singapore. https://doi.org/10.1007/978981-13-2262-4_172-1

Kleine, K., Giones, F., \& Tegtmeier, S. (2019). The learning process in technology entrepreneurship education-insights from an Engineering Degree. Journal of Small Business Management, 57(S1), 94-110. https://doi.org/10.1111/jsbm.12514

Klofsten, M., Fayolle, A., Guerrero, M., Mian, S., Urbano, D., \& Wright, M. (2019). The entrepreneurial university as driver for economic growth and social change: Key strategic challenges. Technological Forecasting and Social Change, 141, 149-158. https://doi.org/10.1016/j.techfore.2018.12.004

Knockaert, M., Ucbasaran, D., Wright, M., \& Clarysse, B. (2011). The relationship between knowledge transfer, top management team composition, and performance: The case of science-based entrepreneurial firms. Entrepreneurship Theory and Practice, 35(4), 777-803. https://doi.org/10.1111/j. 1540-6520.2010.00405.x

Kochenkova, A., Grimaldi, R., \& Munari, F. (2016). Public policy measures in support of knowledge transfer activities: A review of academic literature. Journal of Technology Transfer, 41(3), 407429. https://doi.org/10.1007/s10961-015-9416-9

Kotha, R., George, G., \& Srikanth, K. (2013). Bridging the mutual knowledge gap: Coordination and the Commercialization of University Science. Academy of Management Journal, 56(2), 498-524. https://doi.org/10.5465/amj.2010.0948

Kunttu, L. (2017). Educational involvement in innovative university-industry collaboration. Technology Innovation Management Review, 7(12), 14-22. https://doi.org/10.22215/timreview/1124

Lam, A. (2011). What motivates academic scientists to engage in research commercialization: 'Gold', 'ribbon' or 'puzzle'? Research Policy, 40(10), 1354-1368. https://doi.org/10.1016/j.respol.2011.09.002

Langley, A., Smallman, C., Tsoukas, H., \& Van de Ven, A. H. (2013). Process studies of change in organization and management: Unveiling temporality, activity, and flow. Academy of Management Journal, 56(1), 1-13. https://doi.org/10.5465/amj.2013.4001

Löfsten, H., Klofsten, M., \& Cadorin, E. (2020). Science parks and talent attraction management: University students as a strategic resource for innovation and entrepreneurship. European Planning Studies. https://doi.org/10.1080/09654313.2020.1722986

Mangematin, V., O'Reilly, P., \& Cunningham, J. A. (2014). PIs as boundary spanners, science and market shapers. Journal of Technology Transfer, 39(1), 1-10. https://doi.org/10.1007/s10961-012-9270-y

Mankins, J. C. (2009). Technology readiness assessments: A retrospective. Acta Astronautica, 65(9-10), 1216-1223. https://doi.org/10.1016/j.actaastro.2009.03.058

Meoli, M., \& Vismara, S. (2016). University support and the creation of technology and non-technology academic spin-offs. Small Business Economics, 47(2), 345-362. https://doi.org/10.1007/ s11187-016-9721-1

Mitchell, R. K., Mitchell, J. R., Smith, J. B., \& Journal, S. E. (2008). Inside opportunity formation: Enterprise failure, cognition, and the creation of opportunities. Strategic Entrepreneurship Journal, 2(3), 225-242. https://doi.org/10.1002/sej.51

Mustar, P., Wright, M., \& Clarysse, B. (2008). University spin-off firms: Lessons from ten years of experience in Europe. Science and Public Policy, 35(2), 67-80. https://doi.org/10.3152/030234208X282862

Nelson, A. J., \& Monsen, E. (2014). Teaching technology commercialization: Introduction to the special section. The Journal of Technology Transfer, 39(5), 774-779. https://doi.org/10.1007/s10961-014-9341-3

Nilsson, A. S., Rickne, A., \& Bengtsson, L. (2010). Transfer of academic research: Uncovering the grey zone. Journal of Technology Transfer, 35(6), 617-636. https://doi.org/10.1007/s10961-009-9124-4

Perkmann, M., Tartari, V., McKelvey, M., Autio, E., Broström, A., D’Este, P., et al. (2013). Academic engagement and commercialisation: A review of the literature on university-industry relations. Research Policy, 42(2), 423-442. https://doi.org/10.1016/j.respol.2012.09.007

Piperopoulos, P., \& Dimov, D. (2015). Burst bubbles or build steam? Entrepreneurship education, entrepreneurial self-efficacy, and entrepreneurial intentions. Journal of Small Business Management, 53(4), 970-985. https://doi.org/10.1111/jsbm.12116

Rasmussen, E., \& Wright, M. (2015). How can universities facilitate academic spin-offs? An entrepreneurial competency perspective. Journal of Technology Transfer, 40(5), 782-799. https://doi.org/10.1007/ s10961-014-9386-3

Secundo, G., Ndou, V., \& Del Vecchio, P. (2016). Challenges for instilling entrepreneurial mindset in scientists and engineers: What works in european universities? International Journal of Innovation and Technology Management, 13(5), 1-23. https://doi.org/10.1142/S0219877016400125

Siegel, D. S., \& Wright, M. (2015). Academic entrepreneurship: time for a rethink? British Journal of Management, 26(4), 582-595. https://doi.org/10.1111/1467-8551.12116 
Snihur, Y., Lamine, W., \& Wright, M. (2021). Educating engineers to develop new business models: Exploiting entrepreneurial opportunities in technology-based firms. Technological Forecasting and Social Change, 164(November), 119518. https://doi.org/10.1016/j.techfore.2018.11.011

Steinmo, M., \& Rasmussen, E. (2018). The interplay of cognitive and relational social capital dimensions in university-industry collaboration: Overcoming the experience barrier. Research Policy, 47(10), 1964 1974. https://doi.org/10.1016/j.respol.2018.07.004

Thune, T., \& Gulbrandsen, M. (2014). Dynamics of collaboration in university-industry partnerships: Do initial conditions explain development patterns? Journal of Technology Transfer, 39(6), 977-993. https://doi.org/10.1007/s10961-014-9331-5

Thursby, J. G., Jensen, R., \& Thursby, M. C. (2001). Objectives, characteristics and outcomes of university licensing: A survey of major U.S Universities. Journal of Technology Transfer, 26, 59-72. https://doi. org/10.1023/A:1007884111883

Van de Ven, A. H., \& Poole, M. S. (2005). Alternative approaches for studying organizational change. Organization Studies, 26(9), 1377-1404. https://doi.org/10.1177/0170840605056907

Villani, E., Rasmussen, E., \& Grimaldi, R. (2017). How intermediary organizations facilitate universityindustry technology transfer: A proximity approach. Technological Forecasting and Social Change, 114, 86-102. https://doi.org/10.1016/j.techfore.2016.06.004

Walter, T., Ihl, C., Mauer, R., \& Brettel, M. (2018). Grace, gold, or glory? Exploring incentives for invention disclosure in the university context. The Journal of Technology Transfer, 43(6), 1725-1759. https://doi. org/10.1007/s10961-013-9303-1

Weckowska, D. M., Molas-Gallart, J., Tang, P., Twigg, D., Castro-Martínez, E., Kijeńska-Dąbrowska, I., et al. (2018). University patenting and technology commercialization-legal frameworks and the importance of local practice. $R \& D$ Management, 48(1), 88-108. https://doi.org/10.1111/radm.12123

Wiklund, J., Hatak, I., Patzelt, H., \& Shepherd, D. A. (2018). Mental disorders in the entrepreneurship context: When being different can be an advantage. Academy of Management Perspectives, 32(2), 182206. https://doi.org/10.5465/amp.2017.0063

Woolley, J. L. (2014). The creation and configuration of infrastructure for entrepreneurship in emerging domains of activity. Entrepreneurship Theory and Practice, 38(4), 721-747. https://doi.org/10.1111/ etap. 12017

Wright, M., Hmieleski, K. M., Siegel, D. S., \& Ensley, M. D. (2007). The role of human capital in technological entrepreneurship. Entrepreneurship Theory and Practice, 31(6), 791-806. https://doi.org/10. $1111 / \mathrm{j} .1540-6520.2007 .00202 . x$

Würmseher, M. (2017). To each his own: Matching different entrepreneurial models to the academic scientist's individual needs. Technovation, 59(October 2016), 1-17. https://doi.org/10.1016/j.technovation. 2016.10.002

Publisher's Note Springer Nature remains neutral with regard to jurisdictional claims in published maps and institutional affiliations. 